lunar elevation were used to construct a $2^{\circ}$ by $2^{\circ}$ grid of topography complete for latitudes less than $75^{\circ}$ from the equator ${ }^{2}$ $\left(1^{\circ}\right.$ of latitude on the Moon is about 30 $\mathrm{km})$. Information on the lunar gravity field was obtained from measurements of Doppler shifts in the frequency of the radio signal transmitted to Earth by the spacecraft, and the new observations were combined with data from earlier orbiters to produce a spherical harmonic representation of the gravity field ${ }^{2}$ complete to harmonic degree and order 70 (corresponding to spatial wavelengths of about $150 \mathrm{~km}$ and greater).

The first surprise was a greater than expected topographic relief. Lunar elevation varies by $16 \mathrm{~km}$, a figure more than 30 per cent greater than the relief known from earlier measurements. Both the topography and the gravity fields show clear anomalies over many impact basins, including several features only tentatively identified as basins before the Clementine data provided confirming evidence ${ }^{3}$. The most pronounced topographic feature on the Moon is the South Pole-Aitken basin ${ }^{5}$, which at $2,500 \mathrm{~km}$ diameter and 8 $\mathrm{km}$ deeper than the lunar reference surface is now championed as the largest impact structure in the Solar System ${ }^{2,3}$. The formation of such a large basin by impact may have excavated material from the underlying mantle as well as from the crust. Multispectral imaging by Clementine has verified earlier suggestions that the surface of the South PoleAitken basin floor is richer in ferromagnesian minerals than is typical of lunar highland areas, consistent with an admixed component of mantle material $^{3,4}$.

Another surprise was that the gravity and topography of some impact basins largely unfilled by mare basalt deposits indicate departures from a fully isostatic state that resist easy interpretation. The Mendel-Rydberg basin, for instance, about $600 \mathrm{~km}$ in diameter and $5 \mathrm{~km}$ deep, has a modest gravity anomaly and is consistent with complete isostatic compensation of relief ${ }^{2}$ by a crust left thinner than normal by the collapse of the impactexcavated cavity and subsequent crustal flow. The nearby South Pole-Aitken basin, however, the oldest $t^{5}$ as well as the largest recognized basin on the Moon, seems to be only about 90 per cent compensated ${ }^{2}$. An isostatic state beneath a basin requires that the underlying crustal rocks be sufficiently hot to flow on timescales of a few hundreds of millions of years or less. The variable state of isostasy beneath lunar basins indicates that such conditions were not simply a function of either the age of the cooling Moon or the energy of the impact event (which scales as a power of the basin size). Rather the strength, and presumably the temperature structure, of the Moon's lithosphere dur-

\title{
ZOOLOGY
}

\section{In the eye of the kestrel}

\author{
WINGED raptors - such \\ as this kestrel - are \\ renowned for their \\ keen eyesight. But un. \\ like humans, kestrels \\ can also see in the \\ ultraviolet, and in the \\ report on page 425 of \\ this issue a group at the \\ Universities of Turku
} and Jyväskylä, Finland, demonstrate that this ability is turned to deadly effect when hunting voles. Voles communicate with one another by laying highways through grass and vegetation which they mark with urine and faeces. The world of a vole is dominated by smell: to a vole on its highway, a patch of scent-laden excrement is an informative as a road sign to a motorist. But as Viitala and co-workers show, kestrels can also read the signs and interpret them as measures of vole population density. It turns out that vole waste-products are strong absorbers of ultraviolet light, much stronger than the background of vegetation. Whereas to a human eye, the difference between a vole highway and any other patch of grass is not discernible, a kestrel sees every field as streaked with the marks of vole activity. In behavioural experiments both in the laboratory and in the wild, kestrels took a far greater interest in an environment daubed with ultraviolet-absorbing vole excrement than one without. This finding could explain how kestrels and other raptors always seem to be able to find their vole prey, even in the aftermath of the population 'crashes' so characteristic of northern rodents, when prey is generally scarce.

Henry Gee

ing the time of basin formation must have varied strongly from one locale to another.

A new solution for global crustal thickness has been obtained ${ }^{2}$ under the assumption that all of the variations in the measured gravity field are due to the known topography and to variations in the thickness of a low-density crust (see figure). Although this solution neglects the contribution to the gravity field of highdensity mare basalt deposits, particularly those in the mascon maria, it does provide a first look at global patterns. The far side is characterized by thicker crust than the near side ( 68 versus $60 \mathrm{~km}$ ), but by a lesser amount than in similar solutions obtained from earlier data lacking global coverage ${ }^{7}$. The range in crustal thickness is more than $100 \mathrm{~km}$, and much of that range is to be found in the central far side.

More important is that the paucity of farside mare deposits is seen not to be simply the result of a greater elevation and thicker crust beneath the far side. Rather the small volumes of mare material in the deep depression of the South Pole-Aitken basin indicate that melt generation during the time of mare volcanism must have occurred much less readily in the mantle beneath the central far side than beneath the near $\operatorname{side}^{4}$. Together with the inference of an uneven nearside lithosphere thickness from the variable response to the emplacement of each mascon mare ${ }^{8}$, these results point to a strongly aspherical temperature structure throughout much of the first 1,500 million years of lunar history. The challenge now is to unravel the respective contributions to this heterogeneity from the processes of lunar formation, later large impacts and mantle dynamics.

The first rush of data from Clementine has shown us a Moon that is much more complex in its thermal and mechanical evolution than had been appreciated. Additional findings are likely to be announced as more of the nearly two million digital images obtained during the mission $^{1}$ are sorted, calibrated and analysed. Doubtless the Moon has more remarkable secrets to reveal.

Sean C. Solomon is in the Department of Terrestrial Magnetism, Carnegie Institution of Washington, Washington, DC 20015 , USA.

1. Nozette, S. et al. Science 266, 1835-1839 (1994).

2. Zuber, M. T., Smith, D. E., Lemoine, F. G. \& Neumann, G. A. Science 266, 1839-1843 (1994).

3. Spudis, P. D., Reisse, R. A. \& Gillis, J. J. Science 266 1848-1851 (1994)

4. Lucey, P. G. Spudis, P. D., Zuber, M., Smith, D. \& Malaret E. Science 266. 1855-1858 (1994)

5. Wilhelms, D. E. U.S. Geol. Surv. Prof. Pap. 1348 (1987).

6. Taylor, S. R. Planetary Science: A Lunar Perspective (Lunar Planet. Inst., Houston, 1982)

7. Kaula, W. M., Schubert, G., Lingenfelter, R. E., Sjogren, W. L. \& Wollenhaupt, W. R. Proc. 4th Lunar Sci. Conf 2811-2819 (Pergamon, New York, 1973)

8. Solomon, S. C. \& Head, J. W. Rev. Geophys. Space Phys. 18, 107-141(1980)

9. Muller, P. M. \& Sjogren, W. L. Science 161, 680-684 (1968). 